\title{
Awake Craniotomy and Coaching
}

\author{
Carla Ruis ${ }^{1,2}$, Irene M. C. Huenges Wajer ${ }^{1}$, Pierre A. J. T. Robe ${ }^{1}$, \\ Martine J. E. van Zandvoort ${ }^{1,2}$ \\ ${ }^{1}$ Department of Neurology \& Neurosurgery, Rudolf Magnus Institute of Neuroscience, University Medical \\ Center Utrecht, Utrecht, The Netherlands \\ ${ }^{2}$ Department of Experimental Psychology, Helmholtz Institute, Utrecht University, Utrecht, The Netherlands \\ Email: c.ruis@umcutrecht.nl
}

Received 10 August 2014; revised 10 September 2014; accepted 10 October 2014

Copyright (C) 2014 by authors and Scientific Research Publishing Inc.

This work is licensed under the Creative Commons Attribution International License (CC BY). http://creativecommons.org/licenses/by/4.0/

C) (7) Open Access

\begin{abstract}
Background: The importance of monitoring cognition during awake craniotomy has been well described in previous studies. The relevance of being coached during such a procedure has received less attention and questions still remain unanswered about what factors are the most important herein. Objective: The aim of this study was to qualitatively analyze what factors were, according to our patients, important in being coaching during awake craniotomy. Methods: Twenty-six patients who underwent awake craniotomy received a questionnaire about their experiences during the procedure. The questions concerned different aspects of the pre-operative part, the operation itself and coaching aspects. Answers were qualitatively analyzed by two investigators and per question, different answer categories were made. Results: Two thirds of the 20 patients who responded to the questionnaire reported anxiety in the days before or during the operation, varying from general anxiety for being awake during surgery to anxiety for very specific aspects such as opening the skull. The constant presence of the neuropsychologist and a transparent communication during the procedure were most frequently (65\% of all the answers) reported as helpful in staying calm. Conclusion: Results of this descriptive study show that patients experience different anxieties before and during an awake craniotomy and give more insight into what factors are important for patients in being coached during such an operation. This study gives directions for clinicians in improving their role as a coach.
\end{abstract}

\section{Keywords}

Coaching, Awake Craniotomy, Anxiety, Reassurance, Cognition

\section{Introduction}

The purpose of awake craniotomy is to monitor the activity of eloquent brain areas while removing tumors or 
other lesions that are located in them. This helps to maximize the resection, while preserving neurological functions and quality of life [1]-[3]. Intraoperative mapping was first described and performed around 1900 by Cushing [4] and later by Penfield [5]. During the last several decades, intraoperative mapping was mostly used to monitor motor and language functions [6]. More recently, interest in monitoring other cognitive functions as well during the awake procedure has grown [7]-[9].

Literature research shows that most studies on awake craniotomy mention the importance of measuring cognition, mostly done by a neuropsychologist (e.g., [3] [8]). Fewer studies analyzed patient tolerance and acceptance of awake craniotomy [10] [11]. These studies indicate that patients are comfortable with the experience and show good acceptance of the procedure. Other studies analyzed patients' experiences and perceptions. Those studies give more insights into the feelings patients experienced immediately before, during and after the awake surgery [12] and show that most patients experienced awake craniotomy as positive [13], although other studies, e.g., [14] indicates that patients can also be anxious during the operation. Questions about how to handle these anxieties and how to coach a patient during craniotomy have been underexposed.

We believe that several aspects and causes of patients' awake craniotomy related anxieties are amenable to coaching. Based on this assumption, in our clinic, we followed multiple coaching interventions before and during the awake surgical procedures as building a trustful relation between patient and neuropsychologist, providing comprehensive information about the procedure, teaching relaxation by means of breathing exercises, and providing support and encouragement. To verify our ideas and to fine-tune our role as coaches, we asked our patients about their experiences in two parts of the procedure wherein coaching is highly important, namely the pre-operative stage and during the procedure. Furthermore, we asked them about aspects of reassurance during the complete procedure. This paper describes patients' responses to the questionnaire.

\section{Methods}

This study was approved by the local medical ethics committee. Results of this study were analyzed anonymously. Patients were informed that the data collected in this study were used for improving clinical care and for scientific research.

\subsection{Patients}

Twenty-six patients were included in this study. All patients underwent awake craniotomy between 2012 and 2013 because of a primary brain tumor. Time between craniotomy and enrolment in the study ranged between one and 11 months.

\subsection{Procedures Pre-Operative}

All patients had an extensive work-up before the operation. The neurosurgeon, nurse practitioner and neuropsychologist explained the procedures from their own expertise. The explanation of the neuropsychologist consisted of multifaceted components, subdivided into clarifications about the procedure, communication style during the operation, coping with anxiety and emotions, relaxation techniques (breathing exercises and principles of the cognitive behavioral therapy), and expectations for the future. Thereafter, the neuropsychologist administrated a neuropsychological assessment, existing of standard neuropsychological tests. In addition, specific testing paradigms according to the procedures during the surgery concerning language, working memory, executive functioning (inhibition), visuoperception, sensory motor functions and parietal functions such as calculation were administrated.

\subsection{Surgical Procedures}

Patients were operated under local anesthesia, microscope view and ultrasound and neuronavigation guidance. The procedures were performed in a park-bench position, allowing the patients to relax and to face the neuropsychologist in a comfortable fashion. The head was fixed in a Mayfield clamp. Local anesthesia was obtained using a mix of $5 \mathrm{mg} / \mathrm{ml}$ chirocaine $1: 1 \mathrm{v}: \mathrm{v}$ and $2 \%$ lidocaine with adrenaline 1:200,000 (a total of $32-55 \mathrm{cc}$ for the complete procedure) injected at the pin sites of the Mayfield clamp and in a rectangular fashion around the planned skin incision site. After removal of the bone flap, a local application of the anesthetics mix was also applied onto the dura at the level of the meningeal arteries. Patients also benefited from titrated pain sedation and 
relaxation with remifentanyl and propofol, respectively. Craniotomies were performed using Anspach ${ }^{\circledR}$ highspeed drills and craniotomes, and tumors were removed using conventional microneurosurgical techniques and under constant cortico-subcortical stimulations using a Micromed ${ }^{\circledR}$ cortical stimulator $(50 \mathrm{~Hz}, 1 \mathrm{~ms}, 2$ - 5 mAmps, trains of 3 seconds at the cortical level and continuous stimulations at the subcortical level). None of the patients had to be returned to general anaesthesia.

Monitoring of the cognitive status by means of cognitive tests administrated by the neuropsychologist was feasible in all patients. The order of tasks was dependent on the location of the stimulation and the condition of the patient. Between testing, the neuropsychologist and patient talked about different pre-arranged topics of patient's interest. The neurosurgeon and the neuropsychologist continuously explained to the patient what was happening. When a patient panicked or experienced pain, breathing exercises were used. Patients were motivated and stimulated to keep up their motivation for the ongoing operation. The neuropsychologist sat next to the patient and was present from start until the end of the craniotomy.

\subsection{Questionnaire}

Patients were asked to answer five open questions sent by letter about their experiences during the pre-operative part, the operation itself and coaching aspects.

The questionnaire consisted of the following questions:

Pre-operative part

Can you indicate how much information you wanted to have about the operation?

What worried you the most in the days before the operation?

During the operation

Which moments during the operation were frightening for you?

How did you experience being tested during the operation?

Coaching

Where there specific things during the explanation about the procedure and during the operation itself that made you more at ease?

\subsection{Data Analysis}

Answers of patients were qualitatively analyzed by two researchers. Highly similar answers were placed together in one category. Per question, different categories were made.

\section{Results}

\subsection{Patients}

Twenty of the 26 patients (77\%) returned the questionnaire. There were no differences in mean age or phase of treatment between the patients who responded to the questionnaire in comparison to those who did not. Out of the 20 patients who responded nine were suspected for a low-grade tumor, 11 were suspected for a high-grade tumor (suspected pathology before craniotomy). The mean age of the total group was 52.0 years (range $28-78$ ), and $55 \%$ was male.

\subsection{Questionnaire}

The answers were categorized per question (see Table 1).

\subsubsection{Pre-Operative Part}

Results of the questionnaire show that $45 \%$ of the patients wanted to receive as much information as possible ("I wanted to know exactly what was going to happen and how long it would take"). The majority of patients (55\%) wanted to receive information about the procedure in a variable degree (e.g., "I wanted to know the most important things but I did not want to know any details"). One of the patients reported that the operation was not his primary concern ("I was thinking so much about the consequences of the procedure that the operation itself seemed secondary").

Similarly, patients responded very differently when asked about what aspects of the procedure frightened 
Table 1. Responses of the total patient sample on the questionnaire about the pre-operative part (Questions 1 and 2), the operation (Questions 3 and 4) and coaching aspects (Question 5) of an awake craniotomy $(n=20)$.

Can you indicate how much information you wanted to have about the operation?

As much information as possible

$\begin{array}{ll}45 \% & 9 \\ 30 \% & 6 \\ 5 \% & 1 \\ 20 \% & 4\end{array}$

Other answers

What worried you the most in the days before the operation?

I had no worries

$35 \% \quad 7$

Being awake in general

$20 \%$

That I would panic

$15 \%$

That complications would arise

$10 \% \quad 2$

Specific other things (e.g., opening the skull)

$10 \%$

Other answers

$10 \%$

Which moments during the operation were frightening for you?

I had no moments of increased anxiety

Other specific moments (e.g., epileptic insult, shaking of the body, lowering of blood pressure)

When I was having pain

$15 \% \quad 3$

Being in the same position for a long period

Other answers

How did you experience being tested during the operation?

Positive

It distracted me from the operation

Wearily

Other answers

Were there specific things during the explanation about the procedure and during the operation itself that made you more at ease?

Constant support of neuropsychologist

$40 \% \quad 8$

Transparent manner of communicating, relaxed atmosphere

Relation with neuropsychologist

Clear explanations

Confirmation that I did it well (reassurance)

them most in the days before the operation. Thirty-five percent of our patients did not have any specific worries. The ones who did worry were scared for the procedure in general ("It was frightening for me to stay awake during the procedure") (20\%), or were afraid to lose control ("I was afraid to lose control and to panic", "I thought I was not able to manage it") (15\%). Others were scared of complications ("I was afraid that they would damage something in my head") or reported very specific anxieties ("The most frightening part for me was the part 
where they had to saw").

\subsubsection{During the Operation}

When asked about moments during the operation when the anxiety level increased, one out of every three patients indicated that these moments did not occur. Conversely, specific events such "having an epileptic insult" or "shaking of the body" were experienced as very anxious (30\%). Other anxious moments were related to pain or discomfort ("opening the skull was very painful", "when I experienced pain I kind of panicked", "lying in the same position for a long period was hard to maintain") (30\%).

The administration of tests during the operation was positively evaluated by almost all of our patients. The testing made them not continuously focused on the operation itself ("I was distracted and this was nice"). Only two out of 20 patients experienced the testing part as wearily.

\subsubsection{Coaching}

When patients were asked what made them more at ease in the days before the operation and during the procedure itself, almost half of them indicated that the intensive contact with the neuropsychologist was very important. Frequently given answers were "I was more at ease because I knew someone was right next to me all the time", "It was pleasant that we had constant contact", or "It was pleasant that I had met the neuropsychologist several times before the operation". Likewise, the atmosphere in the operation room was important for our patients ("the open manner of communicating was nice, even as the equivalency", "the relaxed atmosphere was restful") (25\%). Apparently small things were also reported as being of high value, as in "it was comforting that the neuropsychologist was constantly holding my hand".

Notably, there were no differences between patients with suspected low- $(n=9)$ or high-grade tumors $(n=$ $11)$, low $(<50$ years, $n=9)$ or high age $(>50$ years, $n=11)$ and time between the operation and receiving the questionnaire ( $1-4$ months, $n=10$ versus $5-11$ months, $n=10)$ in the amount of information they wanted to receive. Similarly, there were no differences between those groups in the experiences to be tested during an operation and in the aspects that were mentioned as reassuring. However, there were differences between the groups in the amount of reported anxieties. Nearly all patients with a suspected low-grade tumor described anxieties in the days before the operation (almost $90 \%$ of them). Surprisingly, less than half of the patients with a suspected high-grade tumor reported anxieties. Furthermore, in the group of younger patients, more anxieties were reported (almost 90\%) than in older patients (45\%). Finally, patients who underwent the operation more recently described more anxieties $(90 \%)$ than patients for whom the operation was longer ago (45\%).

\section{Discussion}

The importance of measuring cognition during awake craniotomy is well described (e.g., [3] [8]), but coaching aspects during the pre-operative phase and during the operation have been underexposed. Studies that mention the coaching aspect describe it as separate from the cognitive measurements and as the responsibility of a social worker [15] or anesthesiologist. In this study we wanted to explore what aspects are most important in coaching according to our patients.

In the pre-operative stage, patients differ greatly in the amount of information they wanted to receive about the operation. Nearly half of them wanted to know in detail what was going to happen, while one third expressed no need to have detailed information beforehand. Although adjustment of the amount of information in individual cases is good, a minimal amount of information is required. Patients have to know the outlines of what is expected from them and a concrete preparation can be helpful in reducing anxiety levels [16].

With regard to experienced anxiety in the pre-operative stage, it appeared that patients were frightened about very different things. Some patients were anxious about being awake in general, whereas others reported anxiety about very specific things, such as opening the skull. Clinicians should ask about these fears so that possible misperceptions can be avoided and more explanations can be given.

During the operation, the amount of anxiety increased in some patients when they experienced pain or discomfort. Explaining what causes the pain can be helpful even as coaching a patient in coping with it. Our patients did not specifically mention breathing exercises as being helpful.

Two out of every three of our patients were positive about being tested during the operation. Some of them indicated that it distracted them from what was actually happening in the operation room and they experienced 
this as pleasant. Only two out of the 20 patients explicitly stated that testing made them tired.

When asked about coaching aspects, patients were most reassured by the idea that someone was there for them during the whole procedure. Moreover, an open and transparent manner of communicating was also helpful for our patients. Finally, small things, such as holding someone's hand, seemed to be of great value.

Notably, our questionnaire revealed that patients who underwent the operation more recently reported more anxieties than patients for whom the operation took place longer ago. This might be due to the fact that negative experiences fade more to the background as a result of a developing acceptance of the procedure and the situation of having a brain tumor. Furthermore, older patients reported less anxiety than younger patients, which is in line with what was expected, as in general, anxiety declines with age [17]. In our patient sample we also found differences between patients with a suspected low- and high-grade tumor, in which patients with a suspected low-grade tumor reported more anxieties. However, 10 out of 11 patients with a high-grade tumor were older than 50, so the effect of age may bias this result. In a previous study of D'Angelo et al. [18] no differences in state anxiety in patients with low- or high-grade tumors were found. Nevertheless, future research studying the relation between low- and high-grade tumors and coaching aspects would be interesting.

The results of this study are mainly in line with our assumptions, based on experiences of previous operations on how to coach a patient during awake craniotomy. Nevertheless, results of the questionnaire clarified what aspects were most important in coaching someone, according to our patients. Specific things, such as being constantly there for your patients, turned out to be of much more meaning than previously expected and other things, such as breathing techniques, which were less important in the view of our patients. One of the most essential aspects revealed by this study is the relevance of an intensive relation between the neuropsychologist and the patient, while this was reported as the most reassuring. Patients indicate that talking to them, explaining what is happening and coaching them when they are panicking or having pain, are highly important. Investing time in a trustful relationship with your patient appears to be of great relevance.

In line with previous literature about patients' perceptions and acceptance of this kind of procedure [11] [13], most of our patients experienced the awake craniotomy as positive. Nevertheless, our study also revealed anxieties that needed special attention. In addition, pain and discomfort during the operation resulted in moments of increased anxiety. Moments of anxiety and pain during an awake craniotomy are also described in a recent review of Milian, Tatagiba and Feigl [19], even as symptoms of a posttraumatic stress disorder [20]. Because most of these physical discomforts are inevitable, these results underline the importance of being coached during awake craniotomy.

A valid and reliable manner of monitoring cognition is highly dependent on the patients being calm and not bothered by anxieties. In our opinion, monitoring cognition and coaching a patient cannot be seen as two separate tasks, because of the interaction between anxiety and test performance. When a patient experiences a high level of anxiety, the validity of the cognitive assessment is at stake, while anxiety impairs the efficiency of performances [21]. The other way around, cognitive failures are positively correlated with stress and anxiety [22]. Additionally, research of Santini et al. [23] indicates that the fear of pain during awake craniotomy correlates positively with the pain felt during the operation. Psychological support may reduce the amount of sedation, which is especially important in a procedure where patients have to stay awake all the time (awake-awakeawake procedure) [24]. Hence, someone who can calm down and motivate a patient during cognitive testing is highly important, not only for a patient's mood but also for the course of the operation. Additionally, someone who has the expertise to evaluate if patients' failures during cognitive testing are the result of anxiety/stress or refer to an underlying cognitive deficit is required. Moreover, results of our questionnaire show that patients are in need of someone who is there for them all the time. While those aspects are preferably combined in one person, coaching belongs to the neuropsychologist in our opinion.

Qualitative studies such as this can help clinicians to elaborate on their role as a coach. However, coaching a patient during awake craniotomy remains personalized care. The stress and anxiety level of the patient, the way someone copes with frightening situations, and a patient's personality are determinative.

\section{References}

[1] Brown, P.D., Maurer, M.J., Rummans, T.A., Pollock, B.E., Ballman, K.V., Sloan, J.A., Boeve, B.F., Arusell, R.M., Clark, M. and Buckner J.C. (2005) A Prospective Study of Quality of Life in Adults with Newly Diagnosed HighGrade Gliomas: The Impact of the Extent of Resection on Quality of Life and Survival. Neurosurgery, 57, 495-504. http://dx.doi.org/10.1227/01.NEU.0000170562.25335.C7 
[2] Duffau, H., Lopes, M., Arthuis, F., Bitar, A., Sichez, J.-P., Van Effenterre, R. and Capelle, L. (2005) Contribution of Intraoperative Electrical Stimulations in Surgery of Low Grade Gliomas: A Comparative Study between Two Series without (1985-96) and with (1996-2003) Functional Mapping in the Same Institution. Journal of Neurology, Neurosurgery \& Psychiatry, 76, 845-851. http://dx.doi.org/10.1136/jnnp.2004.048520

[3] Duffau, H. (2012) The Challenge to Remove Diffuse Low-Grade Gliomas While Preserving Brain Functions. Acta Neurochirurgica, 154, 569-574. http://dx.doi.org/10.1007/s00701-012-1275-7

[4] Penleton, C., Zaidi, H.A., Chaichana, K.L., Raza, S.M., Carson, B.S., Cohen-Gadol, A.A. and Quinones-Hinojosa, A. (2012) Harvey Cushing's Contributions to Motor Mapping: 1902-1912. Cortex, 48, 7-14. http://dx.doi.org/10.1016/j.cortex.2010.04.006

[5] Penfield, W. and Rasmussen, T. (1950) The Cerebral Cortex of Man: A Clinical Study of Localization of Function. Macmillan, Oxford.

[6] Grossman, R. and Ram, Z. (2014) Awake Craniotomy in Glioma Surgery. European Association of NeuroOncology Magazine, 4, 27-33.

[7] Duffau, H. (2010) Awake Surgery for Non-Language Mapping. Neurosurgery, 66, 523-529. http://dx.doi.org/10.1227/01.NEU.0000364996.97762.73

[8] Szelényi, A., Bello, L., Duffau, H., Fava, E., Feigl, G.C., Galanda, M., Neuloh, G., Signorelli, F. and Sala, F. (2010) Intraoperative Electrical Stimulation in Awake Craniotomy: Methodological Aspects of Current Practice. Neurosurgical Focus, 29, E7. http://dx.doi.org/10.3171/2009.12.FOCUS09237

[9] Wager, M., Du Boisgueheneuc, F., Pluchon, C., Bouyer, C., Stal, V., Bataille, B., Guillevin, C.M. and Gil, R. (2013) Intraoperative Monitoring of an Aspect of Executive Functions: Administration of the Stroop Test in 9 Adult Patients during Awake Surgery for Resection of Frontal Glioma. Neurosurgery, 72, 169-181. http://dx.doi.org/10.1227/NEU.0b013e31827bf1d6

[10] Danks, R.A., Rogers, M., Aglio, L.S., Gugino, L.D. and Black, P.M. (1998) Patient Tolerance of Craniotomy Performed with the Patient under Local Anesthesia and Monitored Conscious Sedation. Neurosurgery, 42, 28-36. http://dx.doi.org/10.1097/00006123-199801000-00006

[11] Wrede, K.H., Stieglitz, L.H., Fiferna, A., Karts, M., Gerganov, V.M., Samii, M., von Gösseln, H.H. and Lüdemann, W.O. (2011) Patient Acceptance of Awake Craniotomy. Clinical Neurology and Neurosurgery, 113, 880-884. http://dx.doi.org/10.1016/j.clineuro.2011.06.010

[12] Palese, A., Skrap, M., Fachin, M., Visioli, S. and Zannini, L. (2008) The Experience of Patients Undergoing Wake Craniotomy. Cancer Nursing, 31, 168-172. http://dx.doi.org/10.1097/01.NCC.0000305699.97625.dc

[13] Khu, K.J., Doglietto, F., Radovanovic, I., Taleb, F., Mendelsohn, D., Zadeh, G. and Bernstein, M. (2010) Patients' Perceptions of Awake and Outpatient Craniotomy for Brain Tumor: A Qualitative Study. Journal of Neurosurgery, 112, 1056-1060. http://dx.doi.org/10.3171/2009.6.JNS09716

[14] Whittle, I.R., Midgley, S., Georges, H., Pringle, A.M. and Taylor, R. (2005) Patient Perceptions of “Awake” Brain Tumour Surgery. Acta Neurochirurgica, 147, 275-277. http://dx.doi.org/10.1007/s00701-004-0445-7

[15] Nossek, E., Matot, O., Shahar, T., Barzilai, O., Rapoport, Y., Gonen, T., Sela, G., Korn, A., Hayat, D. and Ram, Z. (2013) Failed Awake Craniotomy: A Retrospective Analysis in 424 Patients Undergoing Craniotomy for Brain Tumor. Journal of Neurosurgery, 118, 243-249. http://dx.doi.org/10.3171/2012.10.JNS12511

[16] Sime, A.M. (1976) Relationship of Preoperative Fear, Type of Coping, and Information Received about Surgery to Recovery from Surgery. Journal of Personality and Social Psychology, 34, 716-724. http://dx.doi.org/10.1037/0022-3514.34.4.716

[17] Henderson, A.S., Jorm, A.F., Korten, A.E., Jacomb, P., Christensen, H. and Rodgers, B. (1998) Symptoms of Depression and Anxiety during Adult Life: Evidence for a Decline in Prevalence with Age. Psychological Medicine, 28, 1321-1328.

[18] D’Angelo, C. Mirijello, A., Leggio, L., Ferrulli, A., Carotenuto, V., Icolaro, N., Miceli, A., D’Angelo, V., Gasbarrini, G. and Addolorato, G. (2008) State and Trait Anxiety and Depression in Patients with Primary Brain Tumors before and after Sugery: 1-Year Longitudinal Study. Journal of Neurosurgery, 108, 281-286. http://dx.doi.org/10.3171/JNS/2008/108/2/0281

[19] Milian, M., Tatagiba, M. and Feigl, G.C. (2014) Patient Response to Awake Craniotomy-A Summary Overview. Acta Neurochirurgica, 156, 1063-1070. http://dx.doi.org/10.1007/s00701-014-2038-4

[20] Milian, M., Luerding, R., Ploppa, A., Decker, K., Psaras, T., Tatagiba, M., Gharabaghi, A. and Feigl, G.C. (2013) "Imagine Your Neighbor Mows the Lane": A Pilot Study of Psychological Sequelae Due to Awake Craniotomy. Journal of Neurosurgery, 118, 1288-1295. http://dx.doi.org/10.3171/2013.2.JNS121254

[21] Derakshan, N. and Eysenck, M.W. (2009) Anxiety, Processing Efficiency, and Cognitive Performance. European Psychologist, 14, 168-176. http://dx.doi.org/10.1027/1016-9040.14.2.168 
[22] Mahoney, A.M., Dalby, J.T. and King, M. (1998) Cognitive Failures and Stress. Psychological Reports, 82, 14321434. http://dx.doi.org/10.2466/pr0.1998.82.3c.1432

[23] Santini, B., Talacchi, A., Casagrande, F., Casartelli, M., Savazzi, S., Procaccio, F. and Gerosa, M. (2012) Eligibility Criteria and Psychological Profiles in Patient Candidates for Awake Craniotomy: A Pilot Study. Neurosurgery and Anesthesiology, 24, 209-216. http://dx.doi.org/10.1097/ANA.0b013e3182464aec

[24] Hansen, E., Seemann, M., Zech, N., Doenitz, C., Luerding, R. and Brawanski, A. (2013) Awake Craniotomies without Any Sedation: The Awake-Awake-Awake Technique. Acta Neurochirurgica, 155, 1417-1424. http://dx.doi.org/10.1007/s00701-013-1801-2 
Scientific Research Publishing (SCIRP) is one of the largest Open Access journal publishers. It is currently publishing more than 200 open access, online, peer-reviewed journals covering a wide range of academic disciplines. SCIRP serves the worldwide academic communities and contributes to the progress and application of science with its publication.

Other selected journals from SCIRP are listed as below. Submit your manuscript to us via either submit@scirp.org or Online Submission Portal.
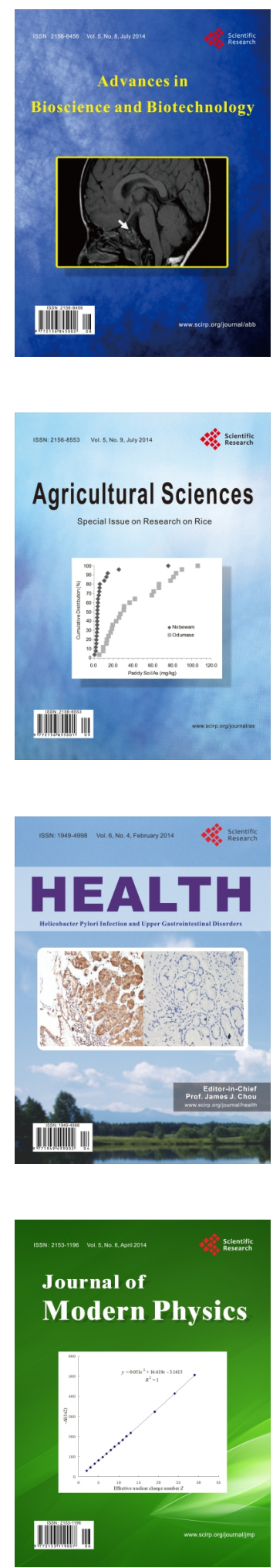
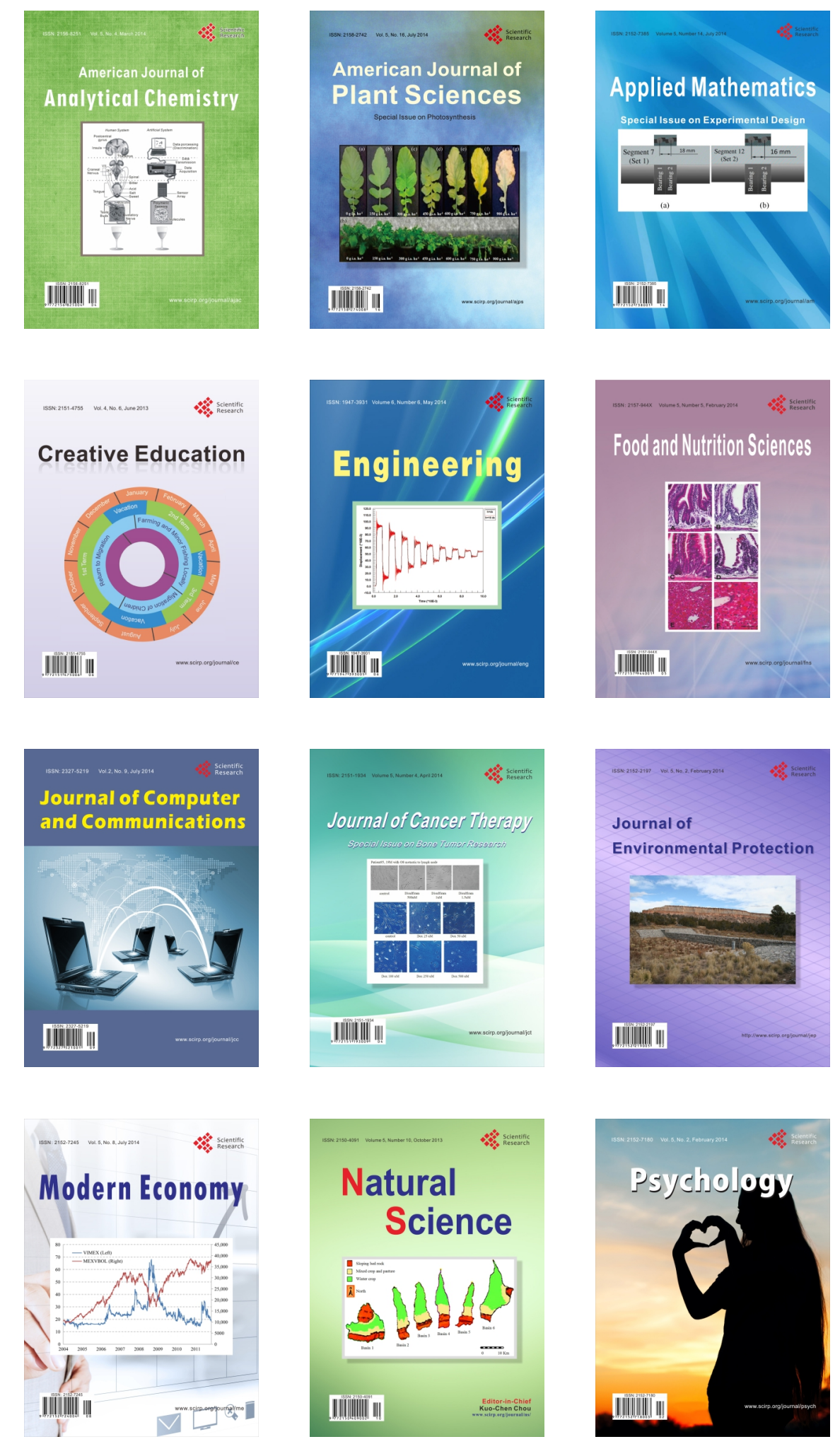